\title{
PHENYLPROPANOIDS AND FATTY ACIDS LEVELS IN ROOTS AND LEAVES OF DATURA STRAMONIUM AND DATURA INNOXIA
}

\section{BILAL RAHMOUNE${ }^{1 \#, ~ I Z Z E D D I N E ~ Z A K A R Y A ~ Z E R R O U K ~}{ }^{1}$, ABDELKADER MORSLI ${ }^{1}$, MADJDA KHELIFI-SLAOUI ${ }^{1}$, LAKHDAR KHELIFI ${ }^{1}$, LUCIANO DO AMARANTE ${ }^{2}$}

${ }_{1}^{1}$ Laboratory of Genetic Resources and Biotechnology-École Nationale Supérieure d'Agronomie (ENSA)-El Harrach-Algiers (Algeria),

${ }^{2}$ Department of Botany, Biology Institute, Federal University of Pelotas, Capão do Leão Campus, P. 0. Box 354, ZIP Code 96010-900, Pelotas, RS, Brazil

Email: b.rahmoun@st.ensa.dz

Received: 30 Oct 2016 Revised and Accepted: 09 May 2017

\begin{abstract}
Objective: The aim of this research was to determine and compare phenylpropanoids and fatty acids composition in two plant species, Datura innoxia and Datura stramonium.

Methods: Phenylpropanoids and fatty acids composition in leaves and roots extracted from Datura innoxia and Datura stramonium, grown under greenhouse conditions, was analyzed by gas chromatography-electron impact/time of flight-mass spectrometry (GC-EI/TOF-MS) chromatography techniques. Analyses were carried out at the Max Planck Institute for Molecular Plant Physiology of Golm (Germany).

Results: We revealed that Datura stramonium (DS) contains hydroxy-hexanedioic acid while hexanoic acid was found in Datura innoxia (DI). Also, two fatty acids are common to both Datura species, hexadecanoic acid and octadecanoic acid, with an almost equal rate between leaves and roots. However, phenylpropanoids composition revealed eight compounds; luteolin, quercetin, trans-caffeic acid, trans-ferulic acid, cis-caffeic acid, cis-4hydroxy-cinnamic acid, trans-4-hydroxy-cinnamic acid and trans-sinapic acid in DI. However, in DS, five compounds were detected: luteolin, quercetin, trans-caffeic acid, trans-ferulic acid and dihydroferulic acid. Also in both Datura species, phenylpropanoids concentration in leaves was significantly higher than in the roots.
\end{abstract}

Conclusion: Our results showed a difference in phenylpropanoids and fatty acids compositions between the two Datura species, with a significantly higher concentration of phenylpropanoids in Datura innoxia than in Datura stramonium

Keywords: Phenylpropanoids, Fatty acids, Datura stramonium, Datura innoxia, GC-EI/TOF-MS

(C) 2017 The Authors. Published by Innovare Academic Sciences Pvt Ltd. This is an open access article under the CC BY license (http://creativecommons.org/licenses/by/4.0/] DOI: http://dx.doi.org/10.22159/ijpps.2017v9i7.15946

\section{INTRODUCTION}

Datura, a member of Solanaceae, is distributed in warm regions of the world [1]. Various species of Datura are known and widely employed for their medicinal and toxic properties based on the presence of tropane alkaloids that are used as parasympatholytics. These compounds, highly used in pharmaceutical industry, are only present in plants [2]. Tropane alkaloids can have critical pharmaceutical applications in small doses; for instance, they are used in making muscle relaxants, painkillers, tranquilizers and psychotropic drugs [3]. In addition to alkaloids, Datura also produces significant metabolites such as phenylpropanoids and fatty acids. Phenylpropanoids are secondary metabolites, particular to plant kingdom, derived from phenylalanine pathway: they are involved in several functions such as fertility, pigmentation, woodiness, protection against biotic and abiotic agents $[4,5]$. Flavonoids are the main phenolic compounds of phenylpropanoids class and consist of several subgroups including flavones (apigenin, luteolin), flavonols (kaempferol, quercetin), flavanones (naringenin, eriodictyol), flavanonols (dihydroquercetin, dihydromyricetin), and isoflavones (daidzein, genistein). Flavonoids are used to enhance renal excretion; they are also used as a treatment of senile cerebral insufficiency, dementia and problem of memory loss [6] In chemistry, a fatty acid is a carboxylic acid with a long aliphatic chain. All fatty acids are primary metabolites present in plants. These include palmitic acid, stearic acid, oleic acid, linoleic and linolenic acid [7]. Most fatty acids present in nature take the form of glycerol esters. They are found in most living organisms where they play a key role in energy storage. Also, some lipid molecules affect the biogenesis and the function of various cell membranes among many other biological functions [8]

The application of gas chromatography-mass spectrometry (GC-MS) to the analysis of metabolites in complex samples has now become routine. It is a useful method for separation and identification of complex mixtures of tropane alkaloids $[9,10]$. Time-of-flight (TOF)GC-MS metabolite profiling is based on highly reproducible electron impact ionization and can be provided by single chromatograms, 200-1000 mass spectral components [11]. It represents, until now, an unknown magnitude of metabolite detection due to a unique combination of high-resolution gas chromatography with a rapid and sensitive time-of-flight mass analyzer $[12,13]$.

To the best of our knowledge, no information is available on phenylpropanoids and fatty acids composition in roots and leaves of Datura stramonium and Datura innoxia, which is the focal point of the present work

\section{MATERIALS AND METHODS}

\section{Plant materials}

Datura stramonium (DS) and Datura innoxia (DI) seeds were harvested in the experimental area of the National School of Agronomy (ENSA-Algiers) (36 $6^{\circ} 43^{\prime} 15^{\prime \prime}$ north, $3^{\circ} 08^{\prime} 59^{\prime \prime}$ East). Before sowing (in loam as substrate), seeds were scarified with nail clipper and glass paper (80 points) for DI and DS respectively [14]. Four weeks later, DI seedlings (10 seedlings) were transferred to pots with loam as substrate and kept for three weeks, then the roots and leaves were collected and dried for $48 \mathrm{~h}$ at $50{ }^{\circ} \mathrm{C}$. On the other hand, Datura stramonium seedlings (10 seedlings) were transferred to a hydroponics system, containing nutritional MS [15] mineral solution without sugar and vitamins (macro-elements, microelements, iron, $\mathrm{pH}$ 5.8). After three weeks, roots and leaves were collected and dried for $48 \mathrm{~h}$ at $60^{\circ} \mathrm{C}$

\section{Chemicals and reagents}

Chemicals and reagents comprise: MS medium (Duchefa Biochimie), Methanol gradient grade for liquid chromatography (Merck), Chloroform for liquid chromatography (Merck), Ribitol (Sigma), DLAlanine, 2,3,3,3-d4 (Sigma), nonadecanoic acid methyl ester (Sigma), 
1.5-mL Safe-lock, tapered-bottom microvial (Eppendorf, Hamburg, Germany) and 2.0-mL Safe-lock, round-bottom microvial (Eppendorf).

\section{Phenylpropanoids and fatty acids extraction}

Dried roots and leaves samples of Datura stramonium and Datura innoxia were pulverized by liquid nitrogen. Phenylpropanoids and fatty acids were extracted from $20 \mathrm{mg}$ powder of roots or leaves in $360 \mu \mathrm{l}$ of mixture made of $300 \mu \mathrm{l}$ pre-cooled methanol, $30 \mu \mathrm{l}$ internal standard solution $\left(2 \mathrm{mg} / \mathrm{ml}^{13} \mathrm{C}_{6}\right.$-sorbitol), and $30 \mu \mathrm{l}$ nonadecanoic acid methyl ester ( $2 \mathrm{mg} \mathrm{ml}^{-1}$ stock in chloroform) followed by vortexing and incubation at $70{ }^{\circ} \mathrm{C}$ for 15 min under shaking. Afterwards, $200 \mu \mathrm{l}$ of chloroform were added, followed by incubation at $37^{\circ} \mathrm{C}$ for 5 min under shaking. After adding $400 \mu \mathrm{l}$ water, the extract was vortexed and the polar phase was separated by centrifugation. Aliquots of $160 \mu \mathrm{l}$ from the polar metabolite fraction were dried by a speed Vac and stored dried under inert gas at $-20{ }^{\circ} \mathrm{C}$ (Protocol given by the group of Applied Metabolome Analysis, Max Planck Institute for Molecular Plant Physiology of Golm (Germany)).

\section{GC-IE-TOF-MS chromatography}

Phenylpropanoids and fatty acids profiling was performed as detailed previously $[16,11]$ by gas chromatography coupled with electron impact ionization/time-of-flight mass spectrometry (GCEI/TOF-MS) using an Agilent 6890N24 gas chromatograph (Agilent
Technologies, Böblingen, Germany; http://www.agilent.com) with $1 / 30$ split and splitless injection of $1 \mu \mathrm{l}$ onto a Factor Four VF- $5 \mathrm{~ms}$ capillary column, $30 \mathrm{~m}$ length, $0.25 \mathrm{~mm}$ inner diameter, $0.25 \mu \mathrm{m}$ film thickness (Varian-Agilent Technologies, Waldbronn, Germany) which was connected to a Pegasus III time-of-flight mass spectrometer (LECO Instrumente $\mathrm{GmbH}$, Mönchengladbach, Germany; http://www.leco.de).

\section{Statistical analysis}

Each compound was analyzed with three replicates and data were statistically assessed by the stander deviation (SD) of the mean values.

\section{RESULTS AND DISCUSSION}

In the present study, we identified phenylpropanoids and fatty acids composition of roots and leaves in Datura stramonium and Datura innoxia

The results showed that four phenylpropanoids are common to DS and DI: luteolin (1), quercetin (2), trans-caffeic acid (3) and transferulic acid (5). Moreover, DS contains dihydroferulic acid (4), whereas DI contains cis-caffeic acid (6), cis-4-hydroxy-cinnamic acid (7), trans-4-hydroxy-cinnamic acid (8) and trans-sinapic acid (9) (table 1). In a study conducted in 2014 by Pant [17], two phenylpropanoids (cis-sinapic acid and trans-ferulic acid), and one fatty acid (octadecanoic acid) were found in Arabidopsis thaliana.

Table 1: Phenylpropanoids composition in Datura stramonium and Datura innoxia

\begin{tabular}{|c|c|c|c|c|c|}
\hline Datura stramonium & $\begin{array}{l}\text { Molecular } \\
\text { formula }\end{array}$ & $\begin{array}{l}\text { Molecular } \\
\text { weight }(\mathrm{g} / \mathrm{mol})\end{array}$ & Datura innoxia & $\begin{array}{l}\text { Molecular } \\
\text { formula }\end{array}$ & $\begin{array}{l}\text { Molecular weight } \\
\text { (g/mol) }\end{array}$ \\
\hline Luteolin (1) & $\mathrm{C}_{15} \mathrm{H}_{10} \mathrm{O}_{6}$ & 286.24 & Luteolin (1) & $\mathrm{C}_{15} \mathrm{H}_{10} \mathrm{O}_{6}$ & 286.24 \\
\hline Quercetin (2) & $\mathrm{C}_{15} \mathrm{H}_{10} \mathrm{O}_{7}$ & 302.236 & Quercetin (2) & $\mathrm{C}_{15} \mathrm{H}_{10} \mathrm{O}_{7}$ & 302.236 \\
\hline Trans-Caffeic acid (3) & $\mathrm{C}_{9} \mathrm{H}_{8} \mathrm{O}_{4}$ & 180.157 & Cis-Caffeic acid (6) & $\mathrm{C}_{9} \mathrm{H}_{8} \mathrm{O}_{4}$ & 180.157 \\
\hline Dihydroferulic acid (4) & $\mathrm{C}_{10} \mathrm{H}_{12} \mathrm{O}_{4}$ & 196.2 & Trans-Caffeic acid (3) & $\mathrm{C}_{9} \mathrm{H}_{8} \mathrm{O}_{4}$ & 180.157 \\
\hline \multirow[t]{4}{*}{ Trans-Ferulic acid (5) } & $\mathrm{C}_{10} \mathrm{H}_{10} \mathrm{O}_{4}$ & 194.18 & Cis-4-hydroxy-Cinnamic acid (7) & $\mathrm{C}_{9} \mathrm{H}_{8} \mathrm{O}_{3}$ & 164.158 \\
\hline & & & Trans-4-hydroxy-Cinnamic acid (8) & $\mathrm{C}_{9} \mathrm{H}_{8} \mathrm{O}_{3}$ & 164.158 \\
\hline & & & Trans-Ferulic acid (5) & $\mathrm{C}_{10} \mathrm{H}_{10} \mathrm{O}_{4}$ & 194.18 \\
\hline & & & Trans-Sinapic acid (9) & $\mathrm{C}_{11} \mathrm{H}_{12} \mathrm{O}_{5}$ & 224.21 \\
\hline
\end{tabular}

The concentration of phenylpropanoids in leaves was higher than that in roots in both species. Compounds1 and 2 , identified in DS and DI, belong to the flavonoids family.

Compound 1 was characterized as luteolin $\left(3^{\prime}, 44^{\prime}, 5\right.$, 7tetrahydroxyflavone) (fig. 1), which is a common flavonoid that exists in many species of plants and organs, including fruits and medicinal herbs [18]. In the leaves of both species, the same amount of luteolin was found, while DS leaves the amount of luteolin was almost three times more than in DS roots. However, no luteolin was found in DI roots (table 2, table 3 ).

Compound 2 was identified as quercetin (sophoretin; meletin; xanthaurine) (fig. 1). The molecular formula of quercetin is $\mathrm{C}_{15} \mathrm{H}_{10} \mathrm{O}_{7}$ with a molecular weight and density of $302,236 \mathrm{~g} / \mathrm{mol}$ and $1,8 \mathrm{~g} / \mathrm{cm}^{3}$, respectively. Quercetin concentration in DS leaves was $0.549 \mathrm{mg} / \mathrm{g}$, which is the double of quantified amount in roots $(0.224 \mathrm{mg} / \mathrm{g})$. Similar to luteolin, quercetin was not detected in DI roots (table 2, table 3).

Compound 3, trans-caffeic acid (3,4-dihydroxyphenyl, acrylic acid) (fig. 1) has the molecular formula $\mathrm{C}_{9} \mathrm{H}_{8} \mathrm{O}_{4}$ and the molecular weight of $180.157 \mathrm{~g} / \mathrm{mol}$. Levels of trans-caffeic acid in leaves were almost the same in both species; however, in roots, only traces were found (table 2, table 3).

Compound 4, dihydro ferulic acid (4-hydroxy-3-methoxybenzenepropanoic acid; 4-hydroxy-3-methoxy-hydrocinnamic acid; $\beta$-3-methoxy-4-hydroxyphenylpropionic acid; 3-methoxyphloretic acid; dihydroconiferylic acid; hydro ferulic acid) (fig. 1), has almost the same amount in both leaves and roots of DS (table 2).

Compound 5was identified as trans-ferulic acid (4-hydroxy-3methoxycinnamic acid; trans-4-hydroxy-3-methoxycinnamic acid) (fig. 1). This compound is a ubiquitous plant constituent that arises from the metabolism of phenylalanine and tyrosine by shikimate pathway in plants [19]. Trans-ferulic acid concentrations in the leaves and roots of DS were $0,767 \mathrm{mg} / \mathrm{g}$ and $0,521 \mathrm{mg} / \mathrm{g}$, respectively. In DI leaves, the concentration was $0.67 \mathrm{mg} / \mathrm{g}$ and only $0.02 \mathrm{mg} / \mathrm{g}$ in the roots (table 2, table 3 ).

Table 2: Composition and levels of phenylpropanoids in Datura stramonium roots and leaves

\begin{tabular}{lll}
\hline Phenylpropanoids & Leaves (mg/g) & Roots (mg/g) \\
\hline Luteolin & $0.6677 \pm 0.2829$ & $0.2782 \pm 0.1373$ \\
Quercetin & $0.5494 \pm 0.2025$ & $0.2246 \pm 0.0987$ \\
Trans-Caffeic acid & $0.5803 \pm 0.08991$ & $0.1759 \pm 0.0492$ \\
Dihydroferulic acid & $1.1961 \pm 0.3370$ & $1.0064 \pm 0.3017$ \\
Trans-Ferulic acid & $0.7676 \pm 0.1158$ & $0.5213 \pm 0.0767$ \\
\hline
\end{tabular}

Data represented as mean \pm SD $(n=3)$. 
Compound 6, cis-caffeic acid (caffeic acid pure, caffeic acid; 3-(3,4dihydroxyphenyl)prop-2-enoic acid; 3-(3,4-Dihydroxyphenyl) acrylic acid) (fig. 1), is an organic compound classified as a hydroxycinnamic acid. It is found in all plants because it is a key intermediate in the biosynthesis of lignin, one of the principal components of plant biomass and its residues [20]. Cis-caffeic acid was present only in the DI leaves with a concentration of $0,371 \mathrm{mg} / \mathrm{g}$ (table 3 ).

Compound 7 was identified as cis-4-hydroxy-cinnamic acid ((2Z)-3-(4hydroxyphenyl) acrylic acid, (2Z)-3-(4-hydroxyphenyl) prop-2-enoic acid) (fig. 1). The molecular formula is $\mathrm{C} 9 \mathrm{H} 803$; with the molecular weight of $164.158 \mathrm{~g} / \mathrm{mol}$. In our study, we recorded the roots content of cis-4-hydroxy-cinnamic acid twice higher than in the leaves of DI (table 3).

Compound 8 was identified as trans-4-hydroxy-cinnamic acid ((2E)3-(4-hydroxyphenyl) acrylic acid; (4-Hydroxycinnamic acid; (E)-p- coumaric acid; 2-Propenoic acid, 3-[4-(trimethylsiloxy)-phenyl)) (fig. 1). DI contents were $0.41 \mathrm{mg} / \mathrm{g}$ and $0.13 \mathrm{mg} / \mathrm{g}$ in leaves and roots, respectively (table 3).

Compound 9, trans-sinapic acid (trans-4-Hydroxy-3,5-dimethoxycinnamic acid) (fig. 1) a small naturally occurring hydroxycinnamic acid and a member of the phenylpropanoids family with a molecular formula $\mathrm{C}_{11} \mathrm{H}_{12} \mathrm{O}_{5}$; and a molecular weight $224.21 \mathrm{~g} / \mathrm{mol}$, was the most abundant phenylpropanoid in the DI leaves. However, it was null in the roots (table 3).

In the second part of this work, the composition and contents of fatty acids in DS and DI were also determined. Hexadecanoic acid and octadecanoic acid were found in DI and DS with approximately equal rates between the leaves and the roots of each species. Additionally, the third fatty acids found in DS and DI were hydroxyl-hexanedioic acid and hexanoic acid respectively (table 4).

Table 3: Composition and levels of phenylpropanoids in Datura innoxia roots and leaves

\begin{tabular}{lll}
\hline Phenylpropanoids & Leaves (mg/g) & Roots (mg/g) \\
\hline Luteolin & $0.6322 \pm 0.2887$ & $0 \pm 0$ \\
Quercetin & $0.6044 \pm 0.2714$ & $0 \pm 0$ \\
Cis-Caffeic acid & $0.3719 \pm 0.0755$ & $0 \pm 0$ \\
Trans-Caffeic acid & $0.5045 \pm 0.0070$ & $0.0106 \pm 0.0033$ \\
Cis-4-hydroxy-Cinnamic acid & $0.5293 \pm 0.0111$ & $0.2944 \pm 0.0419$ \\
Trans-4-hydroxy-Cinnamic acid & $0.4129 \pm 0.0225$ & $0.1391 \pm 0.0153$ \\
Trans-Ferulic acid & $0.6702 \pm 0.0385$ & $0.0297 \pm 0.0035$ \\
Trans-Sinapic acid & $0.9157 \pm 0.1833$ & $0 \pm 0$ \\
\hline
\end{tabular}

Data represented as mean $\pm S D(n=3)$.

Table 4: Fatty acids composition of Datura stramonium and Datura innoxia

\begin{tabular}{llllll}
\hline Datura stramonium & Molecular formula & $\begin{array}{l}\text { Molecular weight } \\
\text { (g/mol) }\end{array}$ & Datura innoxia & Molecular formula & $\begin{array}{l}\text { Molecular weight } \\
\text { (g/mol) }\end{array}$ \\
\hline Hexadecanoic acid (10 & $\mathrm{C}_{16} \mathrm{H}_{32} \mathrm{O}_{2}$ & 256.424 & Hexadecanoic acid $(10)$ & $\mathrm{C}_{16} \mathrm{H}_{32} \mathrm{O}_{2}$ & 256.424 \\
Hydroxy Hexanedioic acid (12) & $\mathrm{C}_{6} \mathrm{H}_{10} \mathrm{O}_{5}$ & 162.140 & Hexanoic acid (13) & $\mathrm{C}_{6} \mathrm{H}_{12} \mathrm{O}_{2}$ & 116.16 \\
Octadecanoic acid (11) & $\mathrm{C}_{18} \mathrm{H}_{36} \mathrm{O}_{2}$ & 284.477 & Octadecanoic acid (11) & $\mathrm{C}_{18} \mathrm{H}_{36} \mathrm{O}_{2}$ & 284.4772 \\
\hline
\end{tabular}

Data represented as mean $\pm S D(n=3)$.

Compound 10 obtained was hexadecanoic acid (palmitic acid, cetylic acid) (fig. 2), the most common fatty acid saturated found in animals, plants and microorganisms [21]. It is the major component of the palm oil. Palmitic acid is used to produce soaps, cosmetics, and release agents. Hexadecanoic acid concentration in the leaves and the roots of DI and in the leaves of DS was almost equal (table 5, table 6). In DS roots, the amount of hexadecanoic acid was found $10 \%$ higher than that in the leaves.

Compound 11, octadecanoic acid (stearic acid) (fig. 2), is one of the most common saturated fatty acids found in nature. Stearic acid is used in the production of detergents, soaps, and cosmetics. This element's rate in DS leaves was $12 \%$ higher than that in roots.
However, its levels in DI roots were higher than those in the leaves: $0.87 \mathrm{mg} / \mathrm{g}$ and $0.81 \mathrm{mg} / \mathrm{g}$ for roots and leaves, respectively (table 5 , table 6).

Compound 12, hydroxy-hexanedioic acid (fig. 2) has a chemical formula $\mathrm{C}_{6} \mathrm{H}_{10} \mathrm{O}_{5}$ with a molecular weight of $162.1406 \mathrm{~g} / \mathrm{mol}$. The hydroxy-hexanedioic acid amounts founded in DS were $0.45 \mathrm{mg} / \mathrm{g}$ and $0.69 \mathrm{mg} / \mathrm{g}$ respectively in leaves and roots (lowest concentration of all identified fatty acids in this study) (table 5).

Compound 13, hexanoic acid (caproic acid) (fig. 2); a hexane-derived carboxylic acid. This compound concentration in leaves and roots of DI were $0.34 \mathrm{mg} / \mathrm{g}$ and $0.19 \mathrm{mg} / \mathrm{g}$ respectively (table 6).

Table 5: Composition and levels of fatty acids in Datura stramonium roots and leaves

\begin{tabular}{lll}
\hline Fatty acids & Leaves (mg/g) & Roots (mg/g) \\
\hline Hexadecanoic acid & $0.9036 \pm 0.1710$ & $0.9968 \pm 0.1175$ \\
Hydroxy-Hexanedioic acid & $0.4544 \pm 0.1025$ & $0.6939 \pm 0.0494$ \\
Octadecanoic acid & $0.8955 \pm 0.1802$ & $0.7986 \pm 0.0872$ \\
\hline
\end{tabular}

Data represented as mean $\pm S D(n=3)$.

Table 6: Composition and levels of fatty acids in Datura innoxia roots and leaves

\begin{tabular}{lll}
\hline Fatty acids & Leaves $\mathbf{( m g / g )}$ & Roots $(\mathbf{m g} / \mathbf{g})$ \\
\hline Hexadecanoic acid & $0.8939 \pm 0.1501$ & $0.9016 \pm 0.2269$ \\
Hexanoic acid & $0.3428 \pm 0.0886$ & $0.1994 \pm 0.0699$ \\
Octadecanoic acid & $0.8186 \pm 0.0375$ & $0.8777 \pm 0.1952$ \\
\hline
\end{tabular}

Data are presented as mean $\pm S D(n=3)$. 
Datura stramonium and Datura innoxia are considered important species in pharmaceutical research because of alkaloids contents with pharmaceutical and medicinal properties. Others chemical compound of this plants, such as phenylpropanoids, flavonoids and fatty acids, have the similar importance of alkaloids, but they are less studied. Analysis of different Datura organs and research on other metabolites (besides alkaloids) may offer a new aspect of research in these areas.

To the best of our knowledge, no information is available on phenylpropanoids and fatty acids compounds in roots and leaves of Datura stramonium and Datura innoxia. However many other plant species are reported to be the producer of these substances. Pant et al. [17] found that Arabidopsis thaliana plants contain two phenylpropanoids, cis-sinapic acid and trans-ferulic acid and the fatty acid octadecanoic acid. N-trans-coumaroyloctopamine, $\mathrm{N}$-transferuloyl octopamine, guaiacylglycerol- $\beta$-ferulic acid ether, guaiacylglycerol- $\beta$-caffeic acid ether, trans-coumaric acid and transferulic acid were identified in garlic skin [22]. While hexadecanoic acid and octadecanoic acid are the fatty acids found in Melissa officinalis [23]. Phytochemical screening of Plectranthus hadiensis revealed the presence of flavonoids (phenylpropanoids) [24].<smiles>O=c1cc(-c2ccc(O)c(O)c2)oc2cc(O)cc(O)c12</smiles><smiles>O=c1c(O)c(-c2ccc(O)c(O)c2)oc2cc(O)cc(O)c12</smiles><smiles>O=C(O)/C=C/c1ccc(O)c(O)c1</smiles><smiles>COc1cc(CCC(=O)O)ccc1O</smiles><smiles>COc1cc(/C=C/C(=O)O)ccc1O</smiles><smiles>O=C(O)/C=C\c1ccc(O)c(O)c1</smiles><smiles>O=C(O)/C=C\c1ccc(O)cc1</smiles><smiles>O=C(O)/C=C/c1ccc(O)cc1</smiles><smiles>COc1cc(/C=C/C(=O)O)cc(OC)c1O</smiles>

Fig. 1: The chemical structure of phenylpropanoids (1-9) from Datura stramonium and Datura innoxia (http://www.chemspider.com)<smiles>CCCCCCCCCCCCCCC(=O)O</smiles>

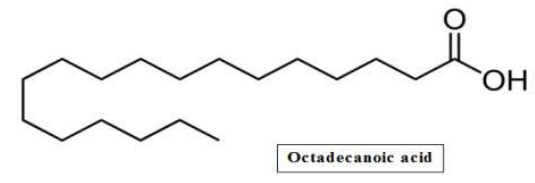<smiles>CCCCCC(=O)O</smiles>

Hexanoic acid

Fig. 2: The chemical structure of fatty acids (10-13) from Datura stramonium and Datura innoxia (http://www.chemspider.com)

\section{CONCLUSION}

Phenylpropanoids and fatty acids are very useful substances in foods and pharmaceuticals industry and their demand sudden increases in recent years. Therefore, improving and increasing production of these substances has become a necessity, which requires more studies and research in Datura and other medicinal plants.

Analysis carried out by the GC-EI/TOF-MS chromatography techniques allowed to identify different phenylpropanoids and fatty acids metabolites in Datura sp. Our studies showed that phenylpropanoids amounts in Datura innoxia were higher than in Datura stramonium and the concentration in leaves is higher than that in roots, in the two species. Our work revealed that DI and DS contain the same fatty acids rates with equal concentrations in the leaves and the roots, but with different components.

The use of modern culture techniques, such as, in vitro or hydroponics systems associated with the application of chemical elicitors or Plant Growth Promoting Rhizobacteria (PGPR) or genetic engineering can optimize the synthesis of specific molecules that are characterized in previous studies of prospection.

\section{ACKNOWLEDGMENT}

This study was supported by the School of agronomy (ENSA)-Algiers (Algeria), the laboratory of Molecular Ecology of the RhizosphereRWTH university of Aachen-(Germany) and the Max Planck Institute for Molecular Plant Physiology of Golm, (Germany). Prof. Joost Van Dongen, Dr. Joachim Kopka and Mr. Alexander Erban are gratefully acknowledged for their precious supervision and help.

The present work is a part of a doctoral thesis of Bilal Rahmoune (the corresponding author), supervised by prof. Khelifi L. and Khelifi-Sellaoui M. Hydroponic system installation, guidance and experimentation in the greenhouse were assured with the help of Dr. Morsli and Dr. Zerrouk IZ. Extraction and preparation of samples for the GC-EI-TOF-MS was carried under the supervision of prof. Luciano Do Amarante. 


\section{CONFLICTS OF INTERESTS}

Authors declare that they have no conflict of interest

\section{REFERENCES}

1. Drake LR, Lin S, Rayson GD, Jackson PJ. Chemical modification and metal binding studies of Datura innoxia. Environ Sci Technol 1995;30:110-4.

2. Griffin WJ, Lin GD. Chemotaxonomy and geographical distribution of tropane alkaloids. Phytochemistry 2000;53:623-37.

3. Hopkins WG. Physiologie végétale. De Boeck Supérieur; 2003.

4. Hahlbrock K, Scheel D. Physiology and molecular biology of phenylpropanoid metabolism. Annu Rev Plant Biol 1989; 40:347-69.

5. Weisshaar B, Jenkins GI. Phenylpropanoid biosynthesis and its regulation. Curr Opin Plant Biol 1998;1:251-7.

6. Máthé Á. Medicinal and Aromatic Plants of the World. Springer; 2015.

7. Seigler DS. Plant secondary metabolism. Springer Science and Business Media; 2012.

8. Browse J, Somerville C. Glycerolipid synthesis: biochemistry and regulation. Annu Rev Plant Biol 1991;42:467-506.

9. Witte L, Müller K, Arfmann HA. Investigation of the alkaloid pattern of Datura innoxia plants by capillary gas-liquidchromatography-mass spectrometry. Planta Med 1987;53:192-7.

10. Ionkova I, Witte L, Alfermann AW. Spectrum of tropane alkaloids in transformed roots of Datura innoxia and Hyoscyamus cultivated in vitro. Planta Med 1994;60:382-4.

11. Erban A, Schauer N, Fernie AR, Kopka J. Nonsupervised construction and application of mass spectral and retention time index libraries from time-of-flight gas chromatographymass spectrometry metabolite profiles. Metabol Methods Protocols 2007;358:19-38.

12. Watson JT, Schultz GA, Tecklenburg RE, Allison J. Renaissance of gas chromatography-time-of-flight mass spectrometry: meeting the challenge of capillary columns with a beam deflection instrument and time array detection. J Chromatogr 1990; 518:283-95.

13. Veriotti T, Sacks R. High-speed GC and GC/time-of-flight MS of lemon and lime oil samples. Anal Chem 2001;73:4395-402.

14. Khelifi-Slaoui M, Rezine R, Amroun S, Khelifi L. Embryons somatiques et bourgeons néoformés induitsur explants issus de vitrosemis de Datura stramonium L. d'origine algérienne.
Actes du séminaire international sur l'amélioration des productions; 2005.

15. Murashige T, Skoog F. A revised medium for rapid growth and bioassays with tobacco tissue cultures. Physiol Plant 1962;15:473-97.

16. Wagner C, Sefkow M, Kopka J. Construction and application of a mass spectral and retention time index database generated from plant GC/EI-TOF-MS metabolite profiles. Phytochemistry 2003;62:887-900.

17. Pant BD, Pant P, Erban A, Huhman D, Kopka J, SCHEIBLE WR. Identification of primary and secondary metabolites with phosphorus status-dependent abundance in arabidopsis, and of the transcription factor PHR1 as a major regulator of metabolic changes during phosphorus limitation. Plant Cell Environ 2015;38:172-87.

18. Lin Y, Shi R, Wang X, Shen HM. Luteolin, a flavonoid with potential for cancer prevention and therapy. Curr Cancer Drug Targets 2008;8:634-46.

19. Srinivasan M, Sudheer AR, Menon VP. Ferulic acid: therapeutic potential through its antioxidant property. J Clin Biochem Nutr 2007;40:92-100.

20. Boerjan W, Ralph J, Baucher M. Lignin biosynthesis. Annu Rev Plant Biol 2003;54:519-46.

21. Gunstone FD, Harwood JL, Dijkstra AJ. The lipid handbook with CD-ROM. CRC Press; 2007.

22. Ichikawa M, Ryu K, Yoshida J, Ide N, Kodera Y, Sasaoka T, et al. Identification of six phenylpropanoids from garlic skin as major antioxidants. J Agric Food Chem 2003;51:7313-7.

23. Kim S, Ju E, Hossain A, Lee H, Kim H. Global profiling of ultraviolet-induced metabolic disruption in Melissa officinalis by using gas chromatography-mass spectrometry. Anal Bioanal Chem 2012;404:553-62.

24. Menon DB, Sasikumar JM. Pharmacognostic study and phytochemical investigation of Plectranthus hadiensis. Int J Pharm Pharm Sci 2011;3:300-4.

\section{How to cite this article}

- $\quad$ Bilal Rahmoune, Izzedine Zakarya Zerrouk, Abdelkadermorsli, Madjda Khelifi-Slaoui, Lakhdar Khelifi, Luciano Do Amarante. Phenylpropanoids and fatty acids levels in roots and leaves of Datura stramonium and Datura innoxia. Int J Pharm Pharm Sci 2017;9(7):150-154. 